\title{
UNLOCKING LATER DEVELOPING LANGUAGE SKILLS IN OLDER CHILDREN BY MEANS OF FOCUSED LANGUAGE STIMULATION
}

\author{
Frenette Southwood, Stellenbosch University \\ Ondene van Dulm, Stellenbosch University
}

Certain language structures and skills continue to develop after the age of school entry. The present study sought to establish whether directly targeting the development of such complex language structures and skills in comprehension and production can be successful among older, school-going children. The data for the present study comprise four case studies of children with language learning problems, including language comprehension problems: one 5, one 6, and two 7 years of age. Relevant parts of the Receptive and Expressive Activities for Language Therapy (Southwood \& Van Dulm, 2012) were used during six to eight language stimulation sessions. Substantial gains were seen when comparing pre-and post-stimulation language assessment results on the Diagnostic Evaluation of Language Variation (Seymour, Roeper, \& De Villiers, 2005). The implication is that direct targeting of specific later developing language structures and skills can render the desired results, well after their usual age of acquisition, even among children with language comprehension problems and within a limited number of sessions. Given the relationship between language skills and the development of reading skills, the findings have implications for the literacy development of Foundation Phase learners who enter school with underdeveloped language skills.

\section{INTRODUCTION}

A large number of South African children enter the school system with underdeveloped language skills (see Klop \& Tuomi, 2007). The present study aimed to ascertain whether targeted language stimulation can assist children in acquiring complex language structures and skills well after the typical age of acquisition of these structures and skills.

Child language development is dependent on the language input the child receives, in two ways. Firstly, in the Chomskyan sense, receiving language input (or primary linguistic data) is necessary to trigger the setting of parameters associated with universal principles (Chomsky, 1995: 170). With sufficient language input, typically developing children are said to acquire native speaker competence in their language around the age of 6 years (Clark, 2000: 181). With insufficient or degraded input, however, the innate, species-specific language acquisition device may be unable to allow for full acquisition of the language. Secondly, the language input a child receives has a direct effect on the vocabulary and syntactic constructions that s/he acquires (Nelson, 1977: 104-105). A child can only acquire those words and sentence types to which s/he has been exposed.

A distinction is made in the literature between simple syntactic skills, which start developing early, and complex syntactic skills, which are later developing and the acquisition of which overlaps with that of simple syntactic skills (Schuele, 2013). A complex sentence is one in which one or more dependent clauses are joined to an independent clause (Quirk, Greenbaum, 
Leech, \& Svartvik, 1985: 987). Complex syntax, however, may be said to comprise more than merely multi-clause sentences. Certain syntactic relations, such as binding relations or those contained in passive constructions, are also syntactically or otherwise complex and/or later developing. Factors influencing the development of complex syntax in child language include

(a) parental input, specifically the frequency with which such syntax occurs in the input (Diessel, 2004: 6). For example, Huttenlocher, Vasilyeva, Cymerman, and Levine (2002: 349) found that the proportion of multi-clause sentences is the best predictor of the occurrence of such sentences in the children's language;

(b) the grammatical complexity of the emerging constructions (Diessel, 2004: 6);

(c) the cognitive development of the child at the time of receiving the input, including the child's theory of mind (Diessel, 2004: 7); and

(d) the age and socioeconomic status of the child, the latter influencing the nature of the parental language input (Hoff-Ginsberg, 1991: 783).

In addition to the role of parental input (see (a) and (d) above), note that classroom language input may also play a role in the development of complex language skills, which continue to develop throughout the early school years and require the ongoing cognitive development mentioned in (c) above. Language input in the home environment differs from that in the classroom environment, in the sense that the latter (a) is less contextualized (see Naremore, Densmore, \& Harman, 1995: xi) and (b) contains more complex and low frequency words and more multi-lexemic expressions (Nippold, 2004: 6). Furthermore, the function of certain syntactic structures may differ in the two contexts. For example, Romaine (1984: 174-175) concluded that although children in a low socioeconomic schooling context were asked questions at home, (a) they had not necessarily learned to respond to interrogative constructions that had a directive pragmatic function, (b) questions that required them to provide information already known to the teacher were not part of their everyday life experiences, and (c) they had little or no experience with questions requiring a display of specific skill and content information evident from books or ways of talking about books.

Whereas classroom talk does contain complex syntax, such complex syntax forms only approximately $20 \%$ of teacher talk at the preschool level (see Dunn Davison, Schuele, Fisher, Combs, Krimm, \& Dickinson, 2012), with large variability across teachers. Dunn Davison et al. (2012) found that the mean proportion of teacher utterances that included complex syntax was $0.19(\mathrm{SD}=0.09)$, with a range of 0.05 to 0.53 . Thus, whereas language input of a certain nature is important for the acquisition of complex language, not all children receive an equal amount of such input in the school setting, nor do they necessarily receive such input before entering school. The quantity of language to which a child is exposed at home varies from parent to parent and from situation to situation (see Hart \& Risley, 1992; Rodriguez \& TamisLemonda, 2011; Rowe, 2012). Furthermore, the child's language level in turn affects the input that the child receives (Sokolov, 1993). For instance, Barnes, Gutfreund, Satterly, and Wells (1983) found that differences in the quantity of parental input were directly proportional to the mean length of utterance and general developmental level of the child.

For the above reasons, amongst others, certain children reach school-age with substantially poorer complex language skills than the majority of their peers. These children include those with language impairment (Tomblin, Records, Buckwalter, Zhang, Smith, \& O’Brien, 1997) as well as those from low socioeconomic backgrounds (Van Hees, 2011).

In the case of children from low socioeconomic backgrounds, the reason for the nonacquisition of certain complex language structures is likely a lack of exposure in their home 
environment (see Hart \& Risley, 1995). In contrast, children with language impairment exhibit an inherent language acquisition problem which may account for their nonacquisition. The question arises as to whether deliberate targeted input can assist the acquisition of complex syntax in school beginners, even those with such language impairment.

Reviews and meta-analyses of studies on intervention for child language disorder and delay have revealed mixed results in terms of the success of such intervention. For instance, Law, Garrett, and Nye (2004: 929) found that effect size estimates did not show a significant difference in the production of syntax between children receiving language interventions and those receiving no treatment, although the effect size did increase when studies covering a period of fewer than eight weeks were removed from the analysis. Furthermore, there were no significant differences between language interventions and no intervention in terms of the impact of such interventions when measured in total number of utterances, mean length of utterance, and parental report of phrase complexity. However, when studies that explicitly involved only children with severe language comprehension difficulties were excluded, the effect estimate significantly favoured language intervention over no intervention, and there were significant differences in the abovementioned three measures. Finally, for outcomes in terms of the comprehension of syntax, the effect estimate showed no significant differences between language interventions and no treatment, as was the case for outcomes in terms of the production of syntax. Thus, not all types of intervention are equally successful at remediating language problems in the syntactic domain, and Law et al. (2004: 935) state that there is a need for studies that include children with severe language comprehension difficulties.

\section{RESEARCH QUESTION}

In light of the above discussion, the research question to be addressed by the present study concerns the extent to which language stimulation directly targeting the comprehension and production of specific complex language structures and skills can assist in their development well after their typical age of acquisition among children with language impairment, including severe language comprehension difficulties. Data to inform this question were collected by means of case studies, as discussed below.

\section{METHODOLOGY}

\section{Study design}

The work reported here was a small-scale exploratory study with a case study design. Four cases (those of one five-year-old, one six-year-old, and two seven-year-olds) are discussed in detail in the Results and Discussion section. We were specifically interested in establishing whether the approach to language stimulation would work for children with challenges in terms of first language acquisition, because if the approach proved successful in these atypical cases, one might predict with a high level of confidence that it would also work for children without language impairment. For this reason, speech-language therapists experienced in treating children with language problems were approached to take part in the study. They identified children on their case loads who were receiving intervention for language disorder. All four children identified for participation by the therapists were Afrikaans-speaking. Participants underwent pretesting by their therapists with the Afrikaans version of the Diagnostic Evaluation of Language Variation - Norm Referenced (DELV; Seymour et al., 2005; see Van Dulm \& Southwood, 2008, for details on the Afrikaans adaptation), a 
comprehensive language assessment instrument (see below). Based on the results of the DELV, the authors in consultation with each speech-language therapist selected areas to focus on during language stimulation with each participant. Speech-language therapists were chosen to provide the intervention in this study because they were familiar with the participants of the study and could provide us with indirect, anonymized access to them. Note, however, that a review by Law et al. (2004: 929) found that there is no significant difference between the success of intervention given by speech-language therapists and that provided by their parents. The material used during language stimulation was in all cases the relevant parts of the Afrikaans version of the Receptive and Expressive Activities for Language Therapy (REALt; Southwood \& Van Dulm, 2012), discussed below.

The focused language stimulation took place for a minimum of six and a maximum of eight sessions over a period of six to 15 weeks. Review studies leave it unclear what exact length of intervention increases its effectiveness. There are indications that intervention periods of more than eight weeks are more effective than those lasting less than eight weeks, but no clear conclusion can be drawn, because longer intervention periods did not necessarily result in more cumulative hours of contact time (see Law et al., 2004). Other reviews have found that intervention as short as four weeks in duration can be effective (see Nye, Foster, Seaman, 1987). We chose an intervention period of six weeks, for practical reasons: We wished the sessions to fit into a single school term so as to avoid long interruptions due to school holidays (although due to illness and other factors, a long interruption became unavoidable in two of the four cases reported here), and the participating speech-language therapists who were offering their service to us free of charge agreed to this intervention period.

The REALt items used during each language stimulation session, the manner in which these items were used, and the child's responses to each item were noted on a record form. Session notes were also made on this form. This allowed for a thorough review of each language stimulation session and for reliable reference during discussion of any unclear matters between the authors and the speech-language therapists.

Following the period of language stimulation with the REALt material, the DELV was readministered. Pre- and post-stimulation composite DELV scores as well as scores per DELV domain were compared for each of the four cases individually. No inter-participant comparisons were made and no group scores were considered.

Note that Fey, Cleave, and Long (1997) found that gains made during a second 4.5-month intervention block were far smaller than those made during the first 4.5-month intervention block. Although the present study involved only one intervention block, the pre-study speechlanguage therapy may in each case be regarded as a first intervention block. We thus expected small gains to result from the focused language stimulation done during our study.

\section{Assessment instrument: Diagnostic Evaluation of Language Variation}

The DELV is a comprehensive test of children's language skills with 11 subtests organized into four domains: syntax, pragmatics, semantics, and phonology. The items of the original American English version of the DELV are the result of extensive research identifying language skills that differentiate between typically developing and language impaired children. The DELV provides a rich assessment of the strengths and weaknesses of a child's language skills, without bias towards speakers of a nonstandard dialect (Seymour et al., 2005: 2-4). 
The syntax domain assesses comprehension of wh questions, comprehension of passive constructions, and production of definite and indefinite articles (Seymour et al., 2005: 2). The pragmatics domain focuses on aspects which are dialect- and culturally-neutral, namely communicative role-taking, asking the correct question to obtain the required information, identifying the correct referent, linking events together in a narrative, and understanding the mental state of characters in a narrative (Seymour et al., 2005: 2). Specifically, this domain assesses narratives (told with the aid of pictures) and question asking. Also included is a subtest on communicative role-taking. In the semantics domain, the focus is on basic processing and organization of information, rather than on specific semantic fields or on the size of the child's vocabulary (Seymour et al., 2005: 2). Specifically, this domain assesses fast mapping of real and new (i.e. nonsense) words, verb contrasts, preposition contrasts, and knowledge of quantifiers. When assessing phonology (the last DELV domain), those aspects which differ amongst the dialects of American English are avoided in the original DELV (Seymour et al., 2005: 86). As such, only consonants are tested, as the pronunciation of vowels varies greatly among dialects. Also, only consonant clusters are assessed, and these occur only in the initial and medial word position in test items, not in the final position, as reduction of word-final consonant clusters occurs under certain conditions in African American English.

The Afrikaans version of the DELV, like the original, assesses (a) syntax (comprehension of wh questions and passive constructions, and correct use of articles), (b) pragmatics (communicative role-taking, linking events together in a narrative and understanding the mental state of characters in a narrative, and asking appropriate questions), (c) semantics (fast mapping of real and new words, producing verb contrasts and preposition contrasts, and knowledge of quantifiers), and (d) phonology (production of consonant clusters in wordinitial and word-medial positions). All children assessed with the DELV perform all tasks for each domain. There are no baseline or ceiling scores; the whole test is administered to each child, regardless of the child's age, gender, or dialect status.

Note that there is a dearth of culturally and linguistically appropriate language assessment instruments for use with Afrikaans-speaking children (see Van Dulm \& Southwood, 2013). Of the three language assessment instruments standardized for use with this population, two assess vocabulary and/or semantic knowledge only, and the third is no longer used by child language practitioners. The DELV is still in the process of being standardized for use with Afrikaans-speaking children, but was selected for use in this study because it assesses many of the skills that the REALt targets and because indications are that the adaptations made to the American version have rendered it suitable for use with South African children. The lack of local norms for the Afrikaans version of the DELV was overcome by comparing each participant's DELV score at one time of testing to only his/her own scores at another time of testing; thus no normative or inter-child comparisons were made.

\section{Intervention material: Receptive and Expressive Activities for Language Intervention}

The REALt was chosen as the intervention instrument in this study because it is the only commercially available language stimulation programme that (a) was devised to be culturally and linguistically appropriate for use with Afrikaans-speaking children and (b) targets later developing language structures and skills. It was specifically developed for use with children aged four to nine years who require deliberate exposure to certain language structures in their first or second language or who exhibit a language delay/disorder. The REALt target structures were developed on the basis of literature on, amongst others, (a) typical language 
development across languages and dialects, and (b) so-called 'school language', which, as stated above, differs from the language to which children are exposed in their home environment in the sense that school language is more decontextualized than language in the home environment.

The REALt consists of colour picture items with accompanying text, grouped into booklets according to the structures and skills that they target. In this study, items targeting the following were used: (a) comprehension and production of articles, (b) comprehension and production of quantifiers, (c) production of conjunctions, (d) comprehension and production of passive constructions, (e) comprehension and production of single and complex wh questions, and (f) narratives and role-taking. Each of the booklets has several subparts, as discussed below.

\section{Articles}

The Articles booklet of the REALt has a comprehension and a production part. Two types of articles are included, namely so-called (a) general vs. specific articles, by which an entity is introduced by using general $a$, after which it is prefaced by specific the (e.g., I stood next to $\underline{a}$ tall man. The man turned to me and said, ...), and (b) part vs. whole articles, by which specific the is used for an entity that forms part of a larger whole already introduced with $a$ (e.g., To open a door, one has to grip the handle firmly) (see Roeper, 2007: 69-76). For general vs. specific articles, items cover both comprehension and production, whereas part vs. whole articles are addressed by production items only. The items for comprehension entail pointing to parts of pictures, and those for production entail picture-based question answering.

\section{Quantifiers}

The REALt includes material for the comprehension and production of the quantifiers any, all, every, some, many/more/most, and none. Comprehension tasks take the form of picture selection and picture-based question answering, whereas production tasks require only picture-based question answering.

\section{Conjunctions}

The REALt contains only production items for conjunctions. Items cover seven earlier developing conjunctions (if, because, before, until, after, while, and since) and five later developing conjunctions (as soon as, whenever, although/even though, once, and unless). Conjunction tasks consist of picture-based sentence completion and story-(re)telling.

\section{Passive constructions}

The REALt provides intervention material for the comprehension and production of agentive or full passives (e.g., The tea was poured by Mrs Zulu), agentless or short passives (e.g., The tea was poured), and reversible passives (e.g., Stevie was pinched by Pam and Pam was pinched by Stevie). Unlikely reversible passives are included, such as John was caught by the big fish vs. The big fish was caught by John, and items include action, perceptual, and psychological verbs. The tasks for passive constructions entail picture selection and picturebased sentence completion.

\section{Wh question constructions}

The REALt contains items targeting the production of single $w h$ questions (containing one $w h$ element, as in Who is Boxer chasing? and Where is Debbie going?), as well as the comprehension and production of three types of complex wh questions. The first type of complex wh question is the conjoined question (e.g., Where is Debbie going and how?) 
Conjoined questions can be viewed as two questions in one (as opposed to the two full questions Where is Debbie going and how is she going there?). To answer such a question correctly, the listener must recognize the syntactic dependencies (in this case, that Debbie is the AGENT or EXPERIENCER, where the GOAL, and how the INSTRUMENT), as well as understanding the elision of is she going there from the second question. The second type of complex $w h$ question included in the REALt is the paired exhaustive question, such as Who ate what?, which requires an exhaustive answer containing all pairs of eaters and eaten items relevant to the question (see Roeper, 2007: 178-180; Seymour et al., 2005: 80). In the third type of complex wh question, the so-called 'barrier question', certain syntactic elements act as barriers to the movement of a wh element (see Roeper, 2004: 46-48; Seymour et al., 2005: 7879). For example, in Where did Debbie say what she ate?, what acts as a barrier to the movement of where, which could only have originated in the first clause (Debbie did say where) and not in the second (Debbie ate). In the case of wh question items, the material requires picture-based question answering for comprehension items and elicited question production for production items.

\section{Narratives and role-taking}

The REALt addresses theory of mind and the ability to take on different communicative roles, including that of asker, complimenter, commander, prohibiter, and teller. The material takes the form of a series of picture-based narrative (re)tell tasks. In the case of theory of mind, each narrative is followed by questions eliciting answers that require the child to exhibit understanding of another's perspective on states or events in false belief scenarios.

\section{ETHICAL PROCEDURES}

Ethical clearance for the study was obtained from the Research Ethics Committee: Humanities of Stellenbosch University (approval number HS1050/2014). The authors had no direct contact with the participants or their parents. The speech-language therapists informed parents of the study and invited them to allow their children to participate. Written information on the study was provided to the parents via the therapists, including information on the purpose and nature of the study, on confidentiality measures to be taken, and on the right to withdraw from the study at any point without supplying a reason. The authors' contact information was provided, should the parents have required further information. Parents consented to their child's existing speech-language therapist assessing the child with the DELV, to the REALt material being used in the child's usual therapy sessions, and to the speech-language therapist sharing with the authors' information from the child's file and details on the relevant language stimulation sessions. Participating children were informed of the purpose of the study and assented in writing to participation. In order to maintain confidentiality and anonymity, participants were assigned pseudonyms by their speechlanguage therapists, and these were the names used (a) on all documentation provided to the authors, and (b) during case study meetings between the therapists and authors. The therapists were all registered with the Health Professions Council of South Africa and had taken an oath binding them to ethical practice.

\section{RESULTS AND DISCUSSION}

\section{Case study 1: Linda Stander (five-year-old girl)}

Linda was aged 5 years 6 months and in Grade $\mathrm{R}$ at the onset of the study. Her teacher referred her for routine language screening by a speech-language therapist when she was 5 
years 4 months. The therapist administered the Afrikaans Receptive Vocabulary Test (Buitendag, 1994), on which she obtained an age equivalent score of 3 years 8 months. The Afrikaans translation of the Renfrew Action Picture Test (RAPT; from the Renfrew Language Scales; Renfrew, 1997) was also administered, which assesses spoken language production. Specifically, it focuses on words used to convey information, i.e., nouns, verbs, and prepositions; present, past and future tenses; irregular forms of plural and past tenses; simple and complex sentence construction; and passive voice (http://www.speechmark.net/actionpicture-test-revised-edition). Because the Afrikaans translation of the RAPT is unstandardized and no norms are available for Afrikaans-speaking children, Linda's responses to the RAPT were interpreted qualitatively instead of quantitatively. Such interpretation indicated that Linda used short, simple, 'jumbled' sentences and a large number of English words, although her family is Afrikaans-speaking. After further informal assessment, the therapist diagnosed a general language delay (for both comprehension and production of language) as well as phonological processing problems. Although no IQ testing had been performed, the speechlanguage therapist regarded Linda as cognitively low functioning. She attended intervention sessions regularly (having had 10 weekly sessions of 30 minutes each prior to the onset of the study).

Linda had eight weekly language stimulation sessions of 30 minutes spread over 10 weeks in which the REALt material was used. Linda's pre- and post-stimulation DELV scores are shown in table 1. Her composite standard score was 84 pre-stimulation, viz. just below normal limits. Her percentile rank for semantics was 25, which is within normal limits, but that for both syntax and pragmatics was 16, which is a borderline, low rank. The REALt material selected for Linda focused on aspects assessed by all three of these DELV domains, namely

(a) articles (comprehension and production), assessed in the syntax domain;

(b) narratives and role-taking (asking, commanding, complimenting, prohibiting, telling; and longer narratives with false belief tasks), assessed in the pragmatics domain; and

(c) quantifiers (any, all, every, some, and none, but not many/more/most), assessed in the semantics domain.

Table 1 indicates that Linda's post-stimulation scores for each DELV domain were higher than her pre-stimulation scores, and her percentile ranks for syntax and pragmatics increased to such an extent that they were no longer borderline abnormally low. The composite scaled score increased from 84 (indicative of a potential language disorder) to 95 (viz. well within normal limits), and the overall percentile rank increased from 14 (indicating language delay/disorder) to 37 , which is within normal limits. 
Table 1. Pre- and post-stimulation DELV scores per domain for Linda Stander

\begin{tabular}{|c|c|c|c|c|c|}
\hline & \multicolumn{4}{|l|}{ Domain } \\
\hline & & Syntax & Pragmatics & Semantics & Composite \\
\hline \multirow{3}{*}{$\begin{array}{l}\text { Pre- } \\
\text { stimulation } \\
\text { (chronological } \\
\text { age: } 5 \text { years } 6 \\
\text { months) }\end{array}$} & $\begin{array}{l}\text { Scaled } \\
\text { score }\end{array}$ & 7 & 7 & 8 & Standardized score: 84 \\
\hline & $\begin{array}{l}\text { Percentile } \\
\text { rank }\end{array}$ & 16 & 16 & 25 & 14 \\
\hline & $\begin{array}{l}\text { Age } \\
\text { equivalent }\end{array}$ & $\begin{array}{l}4 \text { years } 5 \\
\text { months }\end{array}$ & $\begin{array}{l}4 \text { years } 4 \\
\text { months }\end{array}$ & $\begin{array}{l}4 \text { years } 8 \\
\text { months }\end{array}$ & -- \\
\hline \multirow{3}{*}{$\begin{array}{l}\text { Post- } \\
\text { stimulation } \\
\text { (chronological } \\
\text { age: } 5 \text { years } \\
10 \text { months) }\end{array}$} & $\begin{array}{l}\text { Scaled } \\
\text { score }\end{array}$ & 11 & 8 & 9 & Standardized score: 95 \\
\hline & $\begin{array}{l}\text { Percentile } \\
\text { rank }\end{array}$ & 63 & 25 & 37 & 37 \\
\hline & $\begin{array}{l}\text { Age } \\
\text { equivalent }\end{array}$ & $\begin{array}{l}6 \text { years } 5 \\
\text { months }\end{array}$ & $\begin{array}{l}4 \text { years } 11 \\
\text { months }\end{array}$ & $\begin{array}{l}5 \text { years } 5 \\
\text { months }\end{array}$ & -- \\
\hline
\end{tabular}

\section{Case study 2: Karin Steyn (six-year-old girl)}

Karin was 6 years 7 months and in Grade 1 at the commencement of her participation in the study. She was brought to the speech-language therapy practice at 4 years 4 months by her mother, who wanted her to continue with stuttering therapy after the family's relocation from a different part of the country. Since transferring to the local practice, Karin had been diagnosed with ADHD and had been prescribed medication for this condition.

Because the case-history information revealed late onset of talking (e.g., Karin said her first word at 3 years 0 months and started using 2-word utterances at 4 years 0 months), the therapist did a full language assessment. In addition to the part of the assessment that focused on stuttering, the Afrikaans Receptive Vocabulary Test (Buitendag, 1994) was administered, in which Karin achieved an age equivalent score of 2 years 11 months. The unstandardized Afrikaans translation of the RAPT (Renfrew, 1997) was also administered. Results of the RAPT indicated many repetitions of words and phrases, incomplete sentences, and the overuse of general all-purpose nouns. Based on this assessment and other informal assessment measures, the speech-language therapist's diagnosis was a general language delay, articulation problems, phonological problems, and stuttering. Karin had a history of slow progress in language intervention; she acquired new language skills notably slowly, but IQ testing revealed that cognitive functioning was within normal limits. At the onset of the study, she had had approximately 100 weekly intervention sessions of 30 to 45 minutes each during which her therapist worked on articulation, fluency, vocabulary comprehension, and sentence structure in general. Her parents generally did not follow the home programmes provided by the therapist, which resulted in the intervention sessions being the only structured language input that Karin received.

Karin's speech-language therapist used the REALt material for seven weekly language stimulation sessions of 45 minutes each, spread over a period of 13 weeks (including the 3week winter school holiday and some other weeks during which Karin could not attend). Specifically, the SLT made use of the material focusing on

(a) articles (comprehension and production), assessed in the syntax domain of the DELV; 
(b) wh questions (specifically the production of single who-subject, who-object, what, where, why, how, which, and when questions; and the comprehension and production of conjoined and paired exhaustive questions), assessed in the pragmatics domain;

(c) early developing conjunctions (if, because, before, until, after, while, and since), assessed in the pragmatics domain; and

(d) narratives and role-taking (asking, commanding, telling, complimenting, prohibiting; and longer narratives with false belief tasks), also assessed in the pragmatics domain.

By selecting to work on four different structures and skills over seven sessions, the speechlanguage therapist diverged from her usual intervention plan, which entailed focusing on one structure or skill for a large number of sessions. The latter had been the therapist's preferred plan because of the slow progress observed in Karin's language development. The results of pre- and post-stimulation testing with the DELV are summarized in Table 2. Note that Karin's low pre-stimulation scores in the syntax and pragmatics domains led to the decision to focus on these structures and skills during the language stimulation sessions. The data in Table 2 indicate that the percentile rank for syntax remained low (falling just within normal limits) from pre- to post-stimulation testing, and that the rank for the pragmatics domain improved from very low to low but within normal limits. Of interest is the percentile rank for the semantics domain, which decreased from pre- to post-stimulation testing. Although no language stimulation pertaining to this domain was offered over the course of the 13 weeks, a decrease in scaled score and a lower percentage rank were unexpected. Despite the lower score on the semantics domain, however, Karin's composite standard score increased from 71 , which indicated language disorder/delay, to 86 , which falls just within normal limits.

Table 2. Pre- and post-stimulation DELV scores per domain for Karin Steyn

\begin{tabular}{|c|c|c|c|c|c|}
\hline & \multicolumn{4}{|l|}{ Domain } \\
\hline & & Syntax & Pragmatics & Semantics & Composite \\
\hline \multirow{3}{*}{$\begin{array}{l}\text { Pre- } \\
\text { stimulation } \\
\text { (chronological } \\
\text { age: } 6 \text { years } 7 \\
\text { months) }\end{array}$} & $\begin{array}{l}\text { Scaled } \\
\text { score }\end{array}$ & 7 & 2 & 11 & Standardized score: 71 \\
\hline & $\begin{array}{l}\text { Percentile } \\
\text { rank }\end{array}$ & 16 & 0.4 & 63 & 3 \\
\hline & $\begin{array}{l}\text { Age } \\
\text { equivalent }\end{array}$ & $\begin{array}{l}5 \text { years } 2 \\
\text { months }\end{array}$ & $\begin{array}{l}\text { Younger than } \\
4 \text { years } 0 \\
\text { months }\end{array}$ & $\begin{array}{l}7 \text { years } 9 \\
\text { months }\end{array}$ & -- \\
\hline \multirow{3}{*}{$\begin{array}{l}\text { Post- } \\
\text { stimulation } \\
\text { (chronological } \\
\text { age: } 6 \text { years } \\
10 \text { months) }\end{array}$} & $\begin{array}{l}\text { Scaled } \\
\text { score }\end{array}$ & 7 & 7 & 9 & Standardized score: 86 \\
\hline & $\begin{array}{l}\text { Percentile } \\
\text { rank }\end{array}$ & 16 & 16 & 37 & 18 \\
\hline & $\begin{array}{l}\text { Age } \\
\text { equivalent }\end{array}$ & $\begin{array}{l}5 \text { years } 2 \\
\text { months }\end{array}$ & $\begin{array}{l}5 \text { years } 2 \\
\text { months }\end{array}$ & $\begin{array}{l}6 \text { years } 5 \\
\text { months }\end{array}$ & -- \\
\hline
\end{tabular}

\section{Case study 3: Herman Muller (seven-year-old boy)}

Herman, who was in Grade 1 at the time of the study and turned 8 during the course of data collection, was referred for speech-language intervention by his Grade R teacher, who was concerned about his 'poor speech; he sounds like a much younger child'. His mother was concerned about his pronunciation only and at the time of the study remained of the opinion that Herman's language development was typical and thus unproblematic. His mother was 
unable to provide information on Herman's speech and language milestones apart from remembering that he said his first word at age one year.

The speech-language therapist administered the Afrikaans Receptive Vocabulary Test (Buitendag, 1994) qualitatively (thus no standard score or age equivalent could be obtained). She also informally administered the unstandardized Afrikaans translation of the RAPT (Renfrew, 1997), as well as an informal articulation test and other informal assessment measures. The results indicated developmental apraxia of speech (i.e., problems planning, organizing and carrying out movements of the tongue, lips, and jaw so that words can be articulated, resulting in the child experiencing trouble saying what s/he wants to say correctly, fluently and consistently), poor syntax (short, incomplete sentences with incorrect word order at times), and severe phonological processes (i.e., patterned and predictable speech errors, such as the systematic substitution and omission of speech sounds, which renders speech unintelligible to all but the child's regular conversational partners). The therapist's diagnosis was dyspraxia of speech as well as phonological processing problems and a language disorder, including a severe comprehension component. Although some language intervention had taken place prior to this study, the focus of pre-study intervention was on phonological processes (inappropriate fronting and backing of sounds and the reduction of consonant clusters to single consonants or to simpler clusters) and not on language skills in a more general sense.

Based on the results of the pre-intervention DELV results, the following REALt materials were selected for use during intervention:

(a) articles (comprehension and production), assessed in the syntax domain of the DELV;

(b) wh questions (specifically the production of single who-subject, who-object, what, where, why, how, which, and when questions; the comprehension and production of conjoined and paired exhaustive questions; and the comprehension of barrier questions), assessed in the syntax and pragmatics domains; and

(c) narratives and role-taking (asking, commanding, telling, complimenting, prohibiting; and longer narratives with false belief tasks), also assessed in the pragmatics domain.

This material was used during six weekly language stimulation sessions of 30 to 45 minutes each, spanning 15 weeks from start to finish, with a 3-week winter holiday, a 1-week spring break, and several weeks of Herman's absence from therapy due to illness. His pre- and poststimulation DELV scores are presented in Table 3. His pre-stimulation percentile ranks were all lower than 16, suggesting language disorder/delay. Despite not receiving any deliberate attention during language stimulation, the semantics domain showed the largest improvement from pre- to post-stimulation testing. The reason for this is not clear. The bulk of the stimulation time was spent on aspects assessed in the syntax domain. The post-stimulation percentile rank for this domain was 37 , which is within normal limits. The pragmatics domain showed a small improvement, with the post-stimulation percentile rank still indicating language delay/disorder. According to his speech-language therapist, however, Herman showed great improvement in narrative production (assessed as part of the pragmatics domain of the DELV). Prior to language stimulation for the purposes of this study, his narratives consisted of short picture descriptions. Towards the end of the language stimulation period, he started to tell stories with more complex grammatical sentence structure and to include conjunctions in his narratives. 
Table 3. Pre- and post-stimulation DELV scores per domain for Herman Muller

\begin{tabular}{|c|c|c|c|c|c|}
\hline & \multicolumn{4}{|l|}{ Domain } \\
\hline & & Syntax & Pragmatics & Semantics & Composite \\
\hline \multirow{3}{*}{$\begin{array}{l}\text { Pre- } \\
\text { stimulation } \\
\text { (chronological } \\
\text { age: } 7 \text { years } 8 \\
\text { months) }\end{array}$} & $\begin{array}{l}\text { Scaled } \\
\text { score }\end{array}$ & 6 & 7 & 9 & Standardized score: 84 \\
\hline & $\begin{array}{l}\text { Percentile } \\
\text { rank }\end{array}$ & 9 & 2 & 1 & 14 \\
\hline & $\begin{array}{l}\text { Age } \\
\text { equivalent }\end{array}$ & $\begin{array}{l}5 \text { years } 2 \\
\text { months }\end{array}$ & $\begin{array}{l}5 \text { years } 5 \\
\text { months }\end{array}$ & $\begin{array}{l}6 \text { years } 8 \\
\text { months }\end{array}$ & -- \\
\hline \multirow{3}{*}{$\begin{array}{l}\text { Post- } \\
\text { stimulation } \\
\text { (chronological } \\
\text { age: } 8 \text { years } 0 \\
\text { months) }\end{array}$} & $\begin{array}{l}\text { Scaled } \\
\text { score }\end{array}$ & 9 & 5 & 11 & Standardized score: 89 \\
\hline & $\begin{array}{l}\text { Percentile } \\
\text { rank }\end{array}$ & 37 & 5 & 63 & 28 \\
\hline & $\begin{array}{l}\text { Age } \\
\text { equivalent }\end{array}$ & $\begin{array}{l}7 \text { years } 0 \\
\text { months }\end{array}$ & $\begin{array}{l}5 \text { years } \\
\text { months }\end{array}$ & $\begin{array}{l}9 \text { years } 3 \\
\text { months }\end{array}$ & -- \\
\hline
\end{tabular}

\section{Case study 4: Xander Valence (seven-year-old boy)}

Xander had been treated by a child psychologist, because 'he had a lot of trauma in his life', according to his parents. His parents were vague about his speech and language developmental milestones, but reported that they 'sometimes couldn't understand him'. At the time of onset of this study, Xander was in Grade 1, aged 7 years 2 months. He had been referred to the speech-language therapist the previous year by his $\mathrm{Gr} \mathrm{R}$ teacher, due to stuttering and unintelligible speech. The therapist administered the Afrikaans Receptive Vocabulary Test (Buitendag, 1994) qualitatively (thus no standard score or age equivalent could be obtained), the unstandardized Afrikaans translation of the RAPT (Renfrew, 1997), an informal articulation test, and other informal assessment tasks. She found Xander to be an intermediate level stutterer exhibiting severely immature phonological processes, possibly childhood apraxia of speech (see explanation in the section on Herman), disordered syntax and very short sentences (the latter possibly as a compensatory mechanism for stuttering, as he was aware of the fact that he stuttered and tried to avoid it). The speech-language therapist's formal diagnosis was a general language delay (in terms of both comprehension and production), possible dyspraxia, phonological problems, and stuttering. Prior to data collection for this study, the therapist had been working on phonological processes and on the comprehension and production of language in general. Xander had been diagnosed with $\mathrm{ADHD}$ and was on medication for this condition at the time of the study, but he did not consistently use the medication. Whether or not he was medicated severely influenced his cooperation during intervention sessions.

Xander's pre- and post-stimulation DELV scores are presented in Table 4. Pre-stimulation, the percentile rank for semantics was 25 (thus within normal limits), whereas those for both syntax and pragmatics were well below 16 (indicating disorder or a delay in development). For this reason, the following parts of the REALt were used during intervention for the purposes of this study:

(a) wh questions (specifically the production of single who-subject, who-object, what, where, why, how, which, and when questions; the comprehension and production of paired exhaustive questions; and the comprehension of conjoined and barrier questions), assessed in the syntax and pragmatics domains of the DELV; and

(b) narratives and role-taking (asking, commanding, complimenting, prohibiting, telling; and longer narratives with false belief tasks), assessed in the pragmatics domain. 
These materials were used in six weekly language stimulation sessions of 30 to 45 minutes each (depending on Xander's ability to concentrate), spread over a period of six weeks. The speech-language therapist reported that Xander enjoyed the visual material but not the auditory input that accompanied the pictures, possibly because he had difficulty focusing on longer explanations when he was not medicated. When he did take his medication, he was willing to work with the material, but when items became more difficult, he typically complained of being tired. Xander's post-stimulation DELV scores demonstrated percentile ranks higher than 16 for both the syntax and pragmatics domains (as well as for the semantics domain), and his composite score increased from 74 pre-stimulation to 98 post-stimulation, indicating post-stimulation language skills that are well within normal limits for his age.

Table 4. Pre- and post-stimulation DELV scores per domain for Xander Valence

\begin{tabular}{|c|c|c|c|c|c|}
\hline & \multicolumn{4}{|l|}{ Domain } \\
\hline & & Syntax & Pragmatics & Semantics & Composite \\
\hline \multirow{3}{*}{$\begin{array}{l}\text { Pre- } \\
\text { stimulation } \\
\text { (chronological } \\
\text { age: } 7 \text { years } 2 \\
\text { months) }\end{array}$} & $\begin{array}{l}\text { Scaled } \\
\text { score }\end{array}$ & 3 & 5 & 8 & Standardized score: 74 \\
\hline & $\begin{array}{l}\text { Percentile } \\
\text { rank }\end{array}$ & 1 & 5 & 25 & 4 \\
\hline & $\begin{array}{l}\text { Age } \\
\text { equivalent }\end{array}$ & $\begin{array}{l}\text { Younger } \\
\text { than } 4 \\
\text { years } 0 \\
\text { months }\end{array}$ & $\begin{array}{l}4 \text { years } 11 \\
\text { months }\end{array}$ & $\begin{array}{l}5 \text { years } 8 \\
\text { months }\end{array}$ & -- \\
\hline \multirow{3}{*}{$\begin{array}{l}\text { Post- } \\
\text { stimulation } \\
\text { (chronological } \\
\text { age: } 7 \text { years } 6 \\
\text { months) }\end{array}$} & $\begin{array}{l}\text { Scaled } \\
\text { score }\end{array}$ & 10 & 9 & 10 & Standardized score: 98 \\
\hline & $\begin{array}{l}\text { Percentile } \\
\text { rank }\end{array}$ & 50 & 37 & 50 & 45 \\
\hline & $\begin{array}{l}\text { Age } \\
\text { equivalent }\end{array}$ & $\begin{array}{l}7 \text { years } 6 \\
\text { months }\end{array}$ & $\begin{array}{l}6 \text { years } 6 \\
\text { months }\end{array}$ & $\begin{array}{l}7 \text { years } 9 \\
\text { months }\end{array}$ & -- \\
\hline
\end{tabular}

\section{CONCLUSION}

This study examined the cases of four young school-going children with first language acquisition problems who were receiving speech-language therapy. The question addressed was the extent to which language stimulation directly targeting the comprehension and production of specific complex language structures and skills can assist in their development after their typical age of acquisition. To this end, the respective speech-language therapists were asked to identify by means of the DELV specific areas in which the relevant children still showed a deficit, despite having received speech-language therapy, most for an extended period. We then assisted the therapists in selecting language stimulation material appropriate for targeting those specific areas in a deliberate fashion. We bore in mind the call of Fey, Long, and Finestack (2003: 12) to recognize 'existing and potential problems outside the realms of syntax and morphology in [the] preparation and implementation of language intervention and ensur[ing] that such problems receive sufficient direct or indirect attention'. We thus included pragmatic (and, to a lesser extent, semantic) skills as targets for language stimulation. We also deliberately included children who demonstrated language comprehension problems, as a review by Law et al. (2004: 930) found that intervention is less effective for those children who also have language comprehension difficulties. In the present study, a maximum of eight, focused language stimulation sessions were offered with a frequency of maximum once per week, after which the language skills of each child were 
reassessed. The pre- vs. post-stimulation results in general indicate substantial gains in the targeted areas, with most such areas improving to the point of exhibiting percentile ranks indicating no impairment in that domain.

No previous South African studies on language stimulation intervention with school-going children could be traced; most South African studies on the language skills of such children focused on assessment or on monitoring language development (without specific intervention being offered). According to our knowledge, this is the first South African study investigating the effectiveness of focused language stimulation by means of an instrument developed in South Africa. While the findings of this study aided in extending the limited data base on later developing language structures and skills, it had several limitations. One limitation was the small number of case studies included. Replication of the study across a more varied selection of cases (in terms of age and mother tongue) is strongly indicated. A further limitation was that the authors had to rely on speech-language therapists to provide them with the relevant case information, including information on prior assessments and intervention. The study was thus to a certain extent limited by local speech-language therapy practices (such as the lack of routine IQ testing due to its cost, which is for the parents' account, and which therefore cannot be demanded by the therapist). Also, although there are indications that the deliverer of the intervention is not a factor that influences the success of the intervention, it is not clear whether one can necessarily generalize findings obtained via speech-language therapists to situations in which teachers and/or parents will provide the targeted language stimulation. Furthermore, no delayed post-stimulation assessments were performed, and therefore we cannot report whether the observed gains were sustained. A recommendation for future research in this field is therefore to ascertain whether gains observed shortly after the end of intervention are indeed sustained over time.

The main implication of the present findings is that focused language stimulation can successfully aid the development of specific language structures and skills, even if it is offered (a) well after the onset of acquisition of complex syntax, (b) during only a few sessions, (c) over a relatively brief period, and (d) to children with a deficit in language comprehension skills. This is encouraging, considering the number of South African children who enter the school system with less than optimal language skills (see Klop \& Tuomi, 2007).

The present findings point to the possibility of parents and teachers playing a more central role in children's language intervention by means of language stimulation material that directly targets specific structures and skills. As stated above, Law et al. (2004: 929) concluded that there were no significant differences between interventions offered by trained parents and those offered by speech-language therapists. In countries like South Africa, that experience both a shortage of trained speech-language therapists and a high demand for language intervention for school-aged children, parents' use of intervention material specifically targeting later developing language skills may prove to be of great benefit to children who have language problems. Indeed, this issue deserves further direct investigation. Finally, it ought to be investigated whether the intervention provided in this study can be replicated by teachers with groups of learners. If focused group-based language stimulation by teachers proves successful, those learners who enter school with poorly developed language skills and receive such teacher-administered language stimulation may be enabled to reduce the gap between their language skills and those of their classmates, thereby reducing their risk for academic failure. 


\section{ACKNOWLEDGMENTS}

The study was funded by the National Research Foundation of South African and the Research Development Office of Stellenbosch University. The authors alone are responsible for the content and writing of the paper.

\section{REFERENCES}

BARNES, S, M GUTFREUND, D SATTERLY \& G WELLS. 1983. Characteristics of adult speech which predict children's language development. Journal of Child Language, 10:65-84.

BUITENDAG, MM. 1994. Afrikaanse reseptiewe woordeskattoets [Afrikaans receptive vocabulary test]. Pretoria, South Africa: Human Sciences Research Council.

CHOMSKY, N. 1995. The Minimalist Program. Cambridge, Mass.: MIT Press.

CLARK, BA. 2000. First and second language acquisition in early childhood. In Rothenberg, D (Ed.), Issues in early childhood education: Curriculum, teacher education, and dissemination of information. Proceedings of the Lilian Katz Symposium. Champaign, IL: Early Childhood and Parenting (ECAP) Collaborative. 181-188.

DIESSEL, H. 2004. The acquisition of complex sentences. Cambridge, UK: Cambridge University Press.

DUNN DAVISON, M, MM SCHUELE, J FISHER, S COMBS, H KRIMM \& D DICKINSON. 2012. Preschool teacher talk: What relates to more complex syntax. Poster presented at the ASHA Convention, 2012, Atlanta, GA. Available from http://www.mc.vanderbilt.edu/documents/cll/files/Dunn\%20Davidson\%20et\%20al.pdf [Accessed: 1 May 2015]

FEY, ME, PL CLEAVE \& SH LONG. 1997. Two models of grammar facilitation in children with language impairments: Phase 2. Journal of Speech, Language, and Hearing Research, 40:5-19.

FEY, ME, SH LONG, \& LH FINESTACK. 2003. Ten principles of grammar facilitation for children with specific langauge impairments. American Journal of Speech-Language Pathology, 12:3-15.

HART, B \& TR RISLEY. 1992. American parenting of language-learning children: Persisting differences in family-child interactions observed in natural home environments. Developmental Psychology, 28:1096-1105.

HART, B \& TR RISLEY. 1995. Meaningful differences in the everyday experiences of young American children. Baltimore, MD: Paul H. Brookes.

HOFF-GINSBERG, E. 1991. Mother-child conversation in different social classes and communicative settings. Child Development, 62(4):782-796.

HUTTENLOCHER, J, M VASILYEVA, E CYMERMAN \& SC LEVINE. 2002. Language input and child syntax. Cognitive Psychology, 45:337-374.

KLOP, D \& SK TUOMI. 2007. The persistence of language disorders in a group of disadvantaged Grade 3 learners. The South African Journal of Communication Disorders, 54:59-66.

LAW, J, Z GARRETT \& C NYE. 2004. The efficacy of treatment for children with developmental speech and language delay/disorder: A meta-analysis. Journal of Speech, Language, and Hearing Research, 47:924-943.

NAREMORE, RC, AE DENSMORE \& DR HARMAN. 1995. Language intervention with school-aged children. Conversation, narrative, and text. San Diego \& London: Singular Publishing Group. 
NELSON, KE. 1977. Facilitating children's syntax acquisition. Developmental Psychology, 13:101-107.

NIPPOLD, MA. 2004. Research on later language development: International perspectives. In RA Berman (Ed.), Language development across childhood and adolescence. Amsterdam and Philadelphia: John Benjamins. 1-8.

NYE, C, SH FOSTER \& D SEAMAN. 1987. Effectiveness of language intervention with language/learning disabled children. Journal of Speech and Hearing Research, 52:348357.

QUIRK, R, S GREENBAUM, G LEECH \& J SVARTVIK. 1985. A comprehensive grammar of the English language. London: Longman.

RENFREW, C. 1997. Renfrew language scales. Milton Keynes: Speechmark Publishing.

RODRIGUEZ, ET \& CS TAMIS-LEMONDA. 2011. Trajectories of the home learning environment across the first 5 years: Associations with children's vocabulary and literacy skills at prekindergarten. Child Development, 8:1058-1075.

ROEPER, T. 2004. Diagnosing language variations: Underlying principles for syntactic assessment. Seminars in Speech and Language, 25:41-55.

ROEPER, T. 2007. The prism of grammar. Cambridge, Massachusetts: MIT Press.

ROMAINE, S. 1984. The language of children and adolescents. The acquisition of communicative competence. Oxford and New York: Basil Blackwell.

ROWE, ML. 2012. A longitudinal investigation of the role of quantity and quality of childdirected speech in vocabulary development. Child Development, 83:1762-1774.

SCHUELE, CM. 2013. Complex syntax: A summary on research of complex syntax in spoken language development as it relates to clinical practice with preschool and schoolage children. Paper presented at SASHLA Conference, September 2013, Bloemfontein, South Africa.

SEYMOUR, HN, T ROEPER \& J DE VILLIERS. 2005. Diagnostic evaluation of language variation. Norm referenced. San Antonio, TX: Pearson.

SOKOLOV, JI. 1993. A local contingency analysis of the fine-tuning hypothesis. Developmental Psychology, 6:1008-1023.

SOUTHWOOD, F \& O VAN DULM. 2012. Receptive and expressive activities in language therapy. Johannesburg: JvR Psychometrics.

TOMBLIN, J, N RECORDS, P BUCKWALTER, X ZHANG, E SMITH \& M O'BRIEN. 1997. Prevalence of specific language impairment in kindergarten children. Journal of Speech, Language, and Hearing Research, 40:1245-1260.

VAN DULM, O \& F SOUTHWOOD. 2008. Toward a dialect-neutral Afrikaans-medium child language assessment instrument: Test item development. Language Matters, 39:300-315.

VAN DULM, O \& F SOUTHWOOD. 2013. Child language assessment and intervention in multilingual and multicultural South Africa: Findings of a national survey. Stellenbosch Papers in Linguistics, 42:55-76.

VAN HEES, JAG. 2011. Oral expression of five and six year olds in low socioeconomic schools (Doctoral dissertation). Available from https://researchspace.auckland.ac.nz/handle/2292/9792. [Accessed: 19 June 2015]

\section{BIOGRAPHICAL NOTES}

Frenette Southwood is a qualified speech-language therapist and audiologist with an MA in Clinical Linguistics (Stellenbosch University) and a PhD in Linguistics (Radboud University Nijmegen). She has been a lecturer and researcher in the Department of General Linguistics at 
Stellenbosch University since 2000. Her research focuses on the development of culturally and linguistically appropriate child language assessment instruments and on typical and atypical language development in South African children.

Ondene van Dulm studied Speech Therapy and Audiology at Stellenbosch University and was also awarded an MA in Clinical Linguistics by this institution. Her PhD research at Radboud University Nijmegen focused on structural properties of code switching between Afrikaans and English. She worked as lecturer and researcher in the Department of General Linguistics at Stellenbosch University from 1998 to 2008, during which time her research focused on sociolinguistic phenomena related to multilingualism in South Africa. She then joined the Communication Disorders Department at Canterbury University in New Zealand, where she continued her work on culturally and linguistically fair child language assessment and intervention. 